\title{
Extracellular calcium elicits a chemokinetic response from monocytes in vitro and in vivo
}

\author{
Ivona T. Olszak, ${ }^{1}$ Mark C. Poznansky, ${ }^{1}$ Richard H. Evans, ${ }^{1}$ Douglas Olson, ${ }^{1}$ \\ Claudine Kos, ${ }^{2}$ Martin R. Pollak, ${ }^{2}$ Edward M. Brown, ${ }^{3}$ and David T. Scadden ${ }^{1}$ \\ ${ }^{1}$ Partners AIDS Research Center and MGH Cancer Center, Massachusetts General Hospital, \\ ${ }^{2}$ Renal Division, Brigham and Women's Hospital, and \\ ${ }^{3}$ Endocrine-Hypertension Division, Brigham and Women's Hospital, Harvard Medical School, Boston, Massachusetts, USA
}

Address correspondence to: David T. Scadden, Massachusetts General Hospital, 149 13th Street, Room 5212,

Boston, Massachusetts 02129, USA. Phone: (617) 726-5615; Fax: (617) 726-4691; E-mail: scadden.david@mgh.harvard.edu.

Ivona T. Olszak and Mark C. Poznansky contributed equally to this work.

Received for publication March 7, 2000, and accepted March 8, 2000.

Recruitment of macrophages to sites of cell death is critical for induction of an immunologic response. Calcium concentrations in extracellular fluids vary markedly, and are particularly high at sites of injury or infection. We hypothesized that extracellular calcium participates in modulating the immune response, perhaps acting via the seven-transmembrane calcium-sensing receptor $(\mathrm{CaR})$ on mature monocytes/macrophages. We observed a dose-dependent increase in monocyte chemotaxis in response to extracellular calcium or the selective allosteric CaR activator NPS $\mathrm{R}-467$. In contrast, monocytes derived from mice deficient in CaR lacked the normal chemotactic response to a calcium gradient. Notably, CaR activation of monocytes bearing the receptor synergistically augmented the transmigration response of monocytes to the chemokine MCP-1 in association with increased cell-surface expression of its cognate receptor, CCR2. Conversely, stimulation of monocytes with MCP- 1 or SDF- $1 \alpha$ reciprocally increased CaR expression, suggesting a dual-enhancing interaction of $\mathrm{Ca}^{2+}$ with chemokines in recruiting inflammatory cells. Subcutaneous administration in mice of $\mathrm{Ca}^{2+}, \mathrm{MCP}-1$, or (more potently) the combination of $\mathrm{Ca}^{2+}$ and MCP-1, elicited an inflammatory infiltrate consisting of monocytes/macrophages. Thus extracellular calcium functions as an ionic chemokinetic agent capable of modulating the innate immune response in vivo and in vitro by direct and indirect actions on monocytic cells. Calcium deposition may be both consequence and cause of chronic inflammatory changes at sites of injury, infection, and atherosclerosis.

J. Clin. Invest. 105:1299-1305 (2000).

\section{Introduction}

Accumulation of immune cells at sites of injury or infection is a critical dimension of host defense that is achieved by highly conserved mediators of cell adhesion and cell motility. The large family of protein cytokines capable of inducing cell migration is collectively termed chemokines. Chemokines can be produced by virtually every cell type in mammals (1-3). Chemokines mediate their function via seven-transmembrane, G protein-coupled receptors (7-TMR); the absence of either chemokines or their receptors results in marked phenotypic alterations in mice (3-5). These include altered inflammatory responses to pathogenic or allergenic challenges, and mitigated atherosclerotic changes in models of vascular disease (6). Extracellular fluids at sites of injury or infection have been reported to contain high concentrations of calcium (7-9), and chronic inflammatory conditions and atherosclerosis are associated with deposition of calcium salts $(6,10,11)$. The concentration of calcium in such settings can be substantially higher than in the serum (7-9). We hypothesized that such extracel- lular calcium gradients actively participate in modulating the immune response, acting via the calciumsensing receptor $(\mathrm{CaR})$.

The CaR is a member of the 7-TMR superfamily, and is responsive to $\mathrm{Ca}^{2+}$ concentrations within the millimolar range found in extracellular fluids (12). It was originally defined by its role in mediating systemic calcium homeostasis; however, it has since been shown to have pleiotropic effects including altering cellular proliferation, differentiation, and apoptosis (13-16). In hematopoietic cells, it is expressed on mature monocytes/macrophages and subsets of progenitor populations in the bone marrow $(17,18)$. Animals engineered to be deficient in this receptor appear normal at birth, but die with severely elevated blood calcium levels within the first few weeks of life (19, 20). Activation of the receptor is maximal at $5 \mathrm{mM}$ $\mathrm{Ca}^{2+}(13)$, and selective $\mathrm{CaR}$ activators have been developed that efficiently mimic $\mathrm{Ca}^{2+}$-induced activation through an allosteric mechanism (e.g., NPS R467 and its less active stereoisomer, S-467) (21). These agents are low molecular weight compounds known 
as calcimimetics that interact with the CaR's transmembrane domains and potentiate the actions of polycationic agonists (such as $\mathrm{Ca}^{2+}$ itself) that bind to the receptor's amino-terminal extracellular domain. Calcimimetics are currently in clinical trials for treating primary hyperparathyroidism, a disorder in which the CaR is underactive, and represent useful pharmacological tools for assessing the CaR's mediatory role in CaR-expressing cells in which high $\mathrm{Ca}^{2+}$ modulates cellular function. CaR signal transduction is mediated via a pertussis toxin-inhibitable $\mathrm{G}_{i}$ pathway as well as a pertussis toxin-insensitive mechanism that probably involves $\mathrm{G} \alpha_{\mathrm{q} / 11}(22-24)$.

We have recently shown cell-surface expression of the $\mathrm{CaR}$ on adult human CD14+ $\mathrm{PBMC}(17,18,25)$. However, the physiological role of the CaR in mononuclear cells is unknown. We examined whether ionic calcium is a chemokinetic agent for human monocytes, whether this activity is mediated via the $\mathrm{G}$ protein-coupled $\mathrm{CaR}$, and whether interactions with other chemokinetic agents are induced by $\mathrm{CaR}$ activation. We assessed the in vivo consequences of activating the $\mathrm{CaR}$, and noted marked infiltration with monocytes. These data strongly support the role of extracellular calcium in modulating monocyte localization and suggest ionic calcium as a primitive mediator of immune function.

\section{Methods}

Preparation of CD14+PBMC. Low-density cells were isolated from human and mouse peripheral blood using Ficoll-Hypaque (Pharmacia Biotech Inc., Piscataway, New Jersey, USA). CD14 monocytes were purified by sorting on a FACSVantage (Becton Dickinson Immunocytometry Systems, San Jose, California, USA), based on CD14 expression. Purified cells were incubated in either calcium-free medium $(1 \times$ HBSS; Mediatech Inc., Herndon, Virginia, USA) or 1× Iscove's modified Dulbecco's medium (IMDM) (Mediatech Inc.), which contains $1.5 \mathrm{mM} \mathrm{Ca}^{2+}$. The medium was subsequently supplemented with 0.5 $\mathrm{mM}, 1 \mathrm{mM}, 2 \mathrm{mM}, 3 \mathrm{mM}$, or $5 \mathrm{mM} \mathrm{CaCl}_{2}$ (Sigma Chemical Co., St. Louis, Missouri, USA) to achieve the desired level of extracellular calcium, or with $1 \mu \mathrm{M}$ of the selective CaR activator NPS R-467 or its less active stereoisomer, NPS S-467, in $3 \mathrm{mM} \mathrm{Ca}{ }^{2+}$. Cells were incubated for up to 24 hours in $5 \% \mathrm{CO}_{2}$ humidified air. Monocytes were then detached from the plate using a cell scraper. All calcium concentrations shown in the presented data represent the total $\mathrm{Ca}^{2+}$ in the basal medium plus any added $\mathrm{Ca}^{2+}$.

Transmigration assays. Transwells $(5-\mu \mathrm{m}$ pore polycarbonate membrane, $12-\mathrm{mm}$ diameter) (CorningCostar Corp., New York, New York, USA) were used to assess cell migration using an established methodology (25). The concentration of $\mathrm{Ca}^{2+}$ in IMDM in the upper and lower chambers of the Transwell ${ }^{\circledR}$ were adjusted according to a checkerboard analysis of chemotaxis. Calcium concentrations varied from 0-6.5 $\mathrm{mM}$. Purified monocytes $\left(10^{4}\right)$ were then placed in the top chamber with $150 \mu \mathrm{L}$ of IMDM. Five hundred microliters of the medium was added to the bottom of the well, and was supplemented with varying concentrations of $\mathrm{Ca}^{2+}$ or with $\mathrm{Ca}^{2+}$ plus $10 \mathrm{ng} / \mathrm{mL}$ of MCP- $1,100 \mathrm{ng} / \mathrm{mL}$ of SDF- $1 \alpha$, or $10 \mathrm{ng} / \mathrm{mL}$ of MIP$1 \alpha$ (PeproTech Inc., Rocky Hill, New York, USA). Cells were incubated at $37^{\circ} \mathrm{C}$ for 3 hours. To study inhibition of chemotaxis, cells were subsequently incubated with wortmannin $\left(1 \mu \mathrm{M}\right.$ for 20 minutes at $\left.37^{\circ} \mathrm{C}\right)$, herbimycin $\left(1 \mu \mathrm{M}\right.$ for 20 minutes at $\left.37^{\circ} \mathrm{C}\right)$, or genistein $\left(1 \mu \mathrm{g} / \mathrm{mL}\right.$ for 20 minutes at $\left.37^{\circ} \mathrm{C}\right)$ before their use in transmigration assays. At the end of the experiment, cells were harvested from the lower chamber and counted using a hemocytometer.

Cytosolic calcium changes. Purified monocytes were loaded with Indo-1 AM (Molecular Probes Inc., Eugene, Oregon, USA). Cells were collected on a FACSVantage ${ }^{\circledR}$ for 30 seconds to establish a baseline emission value for Indo-1 AM. Chemokine ligands were then added to cells incubated in $\mathrm{Ca}^{2+}$-free media, or supplemented with $1.5 \mathrm{mM}$ or $4.5 \mathrm{mM} \mathrm{CaCl}_{2}$ and either the selective calcium receptor activator NPS R-467 or the less active NPS S-467 $(1 \mu \mathrm{M})$ (a gift of E. Nemeth, NPS Pharmaceuticals Inc., Salt Lake City, Utah, USA). Data acquisition then continued for up to 5 minutes.

Chemokine receptor expression and flow cytometric analysis. Purified monocytes were incubated in $\mathrm{Ca}^{2+}$-free medium supplemented with $1 \mathrm{mM}, 3 \mathrm{mM}$, or $5 \mathrm{mM} \mathrm{CaCl}_{2}$, or with $1.5 \mathrm{mM} \mathrm{CaCl}_{2}$ plus $1 \mu \mathrm{M}$ NPS R-467 or NPS S467. Cells were washed once in PBS with 1\% FCS and then resuspended in $100 \mu \mathrm{L}$ of $\mathrm{Ca}^{2+}$-free PBS. Monoclonal antibody against the CaR was added to the cells, and they were incubated alone or with the CaR peptide for 30 minutes at room temperature. Cells were washed with PBS containing 1\% FCS, resuspended in PBS with $1 \%$ FCS, and incubated for 15 minutes at room temperature with FITC-conjugated anti-mouse IgG. The cells were washed again, and conjugated monoclonal antibody was added and incubated for 15 minutes at room temperature. Monoclonal antibodies used were anti-CXCR4, anti-CCR5 (PharMingen, San Diego, California, USA), anti-CCR2 (R\&D Systems Inc., Minneapolis, Minnesota, USA), anti-CD14, and anti-CD4 (Becton Dickinson Immunocytometry Systems). Stained cells were fixed with $1 \%$ paraformaldehyde and were assayed within 24 hours. Flow cytometric analysis was performed using a dual laser FACSCalibur calibrated with 2- $\mu \mathrm{m}$ CaliBRITE beads (both from Becton Dickinson Immunocytometry Systems). Data acquisition and analysis were performed using CellQuest software (Becton Dickinson Immunocytometry Systems).

Breeding and genotyping of $\mathrm{Cas}^{-/-}$mice. Cas $R^{-/-}$mice were bred as described previously (19). To produce $\mathrm{CaR}^{-/-}$mice for this study, heterozygotic mice were intercrossed. The mice studied were of either $129 \mathrm{~S} 6 / \mathrm{SvEv}$ or $129 \mathrm{S6} / \mathrm{SvEv} / \mathrm{Swiss}$ Webster mixed genetic background. (Mice homozygous for the $C a R$ knockout allele do not live longer than 3 weeks.) Mice were genotyped using the following protocol. A sample 

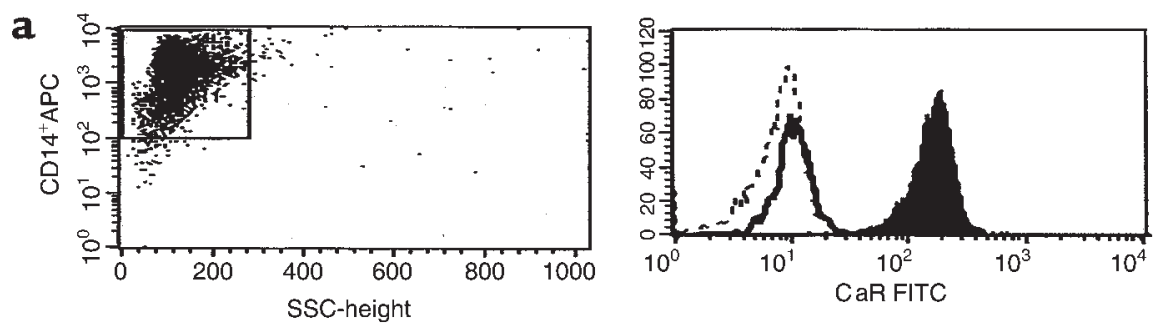

b
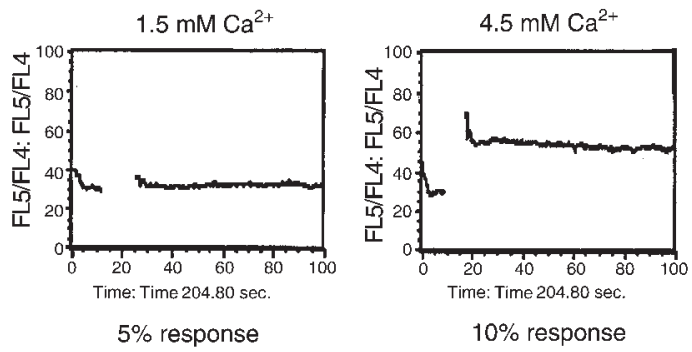

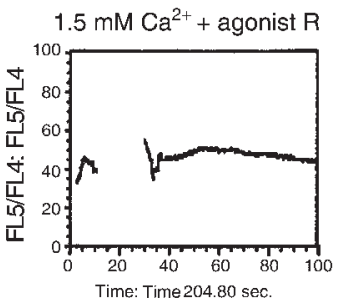

$11 \%$ response

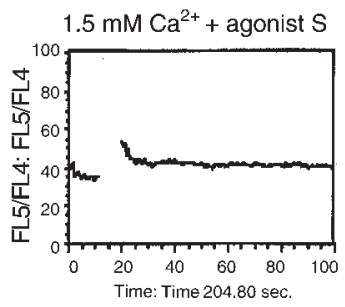

$8 \%$ response

\section{Figure 1}

(a) CD14+ monocytes stain positively for the CaR, and binding of anti-CaR antibody is inhibitable by preincubation with CaR peptide. Purified CD14+ PBMC (scattergram: vertical axis is log fluorescence with allophycocyanin-conjugated anti-CD14; horizontal axis is side scatter) were exposed to anti-CaR antibody (right panel; solid histogram) or isotype control (open histogram) and examined by flow cytometry. Monocytes were also preincubated with CaR peptide before staining with anti-CaR antibody (dashed histogram). Veritical axis is number of events; horizontal axis is log fluorescence with fluorescein isothiocyanate-conjugated anti-CaR. Data represent one of ten independent experiments with comparable results. (b) Elevating the extracellular $\mathrm{Ca}^{2+}$ concentration or adding the selective CaR activator NPS R-467 induces elevation of cytosolic $\mathrm{Ca}^{2+}$. Sustained increases in cytosolic $\mathrm{Ca}^{2+}$ were seen in response to $4.5 \mathrm{mM} \mathrm{Ca}^{2+}$, or $1 \mu \mathrm{M}$ NPS R-467 or S467 in the presence of $1.5 \mathrm{mM} \mathrm{Ca}^{2+}$. All calcium concentrations shown represent the total calcium content of the basal medium plus added calcium. Data are from one of three independent experiments with similar results.

of DNA $(1 \mu \mathrm{L})$ was obtained from a section $(<5 \mathrm{~mm})$ of the tail of each mouse to be genotyped according to established techniques (19). In this way the genotypes of $\mathrm{CaR}^{-/-}, \mathrm{CaR}^{+-}$, and $\mathrm{CaR}^{+/+}$mice were obtained. Peripheral blood was obtained from mice of each genotype at the time of sacrifice on day 6-8 after birth.

Biologic activity of ionic calcium in vivo. C57BL/6 mice (The Jackson Laboratory, Bar Harbor, Maine, USA) were injected subcutaneously at a marked, shaved spot on the abdomen with $20 \mu \mathrm{L}$ of $5 \mathrm{mM} \mathrm{CaCl}_{2}$ or $20 \mu \mathrm{L}$ of MCP-1 at a concentration of $10 \mathrm{ng} / \mathrm{mL}$, with a combination of either MCP-1 and $5 \mathrm{mM} \mathrm{CaCl}$, or $10 \mu \mathrm{M}$ NPS R-467 in PBS. Control mice were injected subcutaneously with $20 \mu \mathrm{L}$ PBS alone. All subcutaneously injected agents contained less than $0.004 \mathrm{ng} / \mathrm{mL}$ of LPS by the limulus assay (Sigma Chemical Co.), as described previously (25). Mice were sacrificed by $\mathrm{CO}_{2}$ asphyxiation 18 hours after injection, and injection sites were excised and snap frozen. From these, $4-\mu \mathrm{m}$ cryosections were obtained and stained with hematoxylin and eosin. Immunocytochemistry was performed on the frozen sections using alkaline phosphatase-conjugated Mac1 antibody (PharMingen) as described previously, and assessed by light microscopy (25).

\section{Results}

Calcium mobilization and chemotaxis. Combining flow cytometry results with our prior data showing the presence of CaR mRNA and protein in monocytes by RT-
PCR and Western analysis, we demonstrated that the $\mathrm{CaR}$ is expressed on the cell surface of PBMC (Figure 1a). We next examined the CaR's functional relevance in monocytes. Extracellular $\mathrm{Ca}^{2+}$ increased the cytosolic $\mathrm{Ca}^{2+}$ concentration in a dose-dependent manner, with a maximal response at $4.5 \mathrm{mM} \mathrm{Ca}^{2+}$ (Figure $1 \mathrm{~b}$ ), consistent with the receptor's known capacity to elevate cytosolic calcium by activating phospholipase C.

A transmigration assay was then used to determine if calcium was capable of inducing monocyte chemotaxis. A dose-dependent effect was seen, with maximal chemotaxis observed at $4.5 \mathrm{mM} \mathrm{Ca}^{2+}$ in a checkerboard analysis of chemotactic response to a concentration gradient of ionic calcium. Chemotaxis was inhibitable by pertussis toxin and by the tyrosine kinase inhibitors herbimycin and genistein, but not by the PI-3 kinase inhibitor wortmannin (Figure 2, a and b). The role of the $\mathrm{CaR}$ in these responses was further assessed by exposure of the cells to spermine, a polycationic $\mathrm{CaR}$ agonist (26), and to the selective CaR activator NPS R467 or its less active stereoisomer, NPS S-467 $(21,27)$. Stimulation of cytosolic calcium responses and transmigration were noted with each of these agents. The greater potency of R-467 than S-467 in enhancing the actions of high $\mathrm{Ca}^{2+}$ on these two biological responses is fully in accord with their known pharmacological actions on the cloned $\mathrm{CaR}$, and strongly support the receptor's role in mediating these actions of extracellular $\mathrm{Ca}^{2+}$ on monocytes (21) (Figure 2c). 
a

\begin{tabular}{|c|c|c|c|c|c|}
\hline & $0 \mathrm{mM}$ & $2 \mathrm{mM}$ & $3.5 \mathrm{mM}$ & $4.5 \mathrm{mM}$ & $6.5 \mathrm{mM}$ \\
\hline $0 \mathrm{mM}$ & $120+/-16$ & $130+/ \cdot 42$ & $200+/-40$ & $200+/-30$ & $600+/-45$ \\
\hline $2 \mathrm{mM}$ & $630+/-78$ & $140+/ \cdot 23$ & $300+/-29$ & $360+/-36$ & $680+/-75$ \\
\hline $3.5 \mathrm{mM}$ & $1,100+/-273$ & $480+/ \cdot 65$ & $180+/-25$ & $480+/-61$ & $720+/-84$ \\
\hline $4.5 \mathrm{mM}$ & $1,800+/-350$ & $790+/ \cdot 61$ & $460+/-56$ & $200+/-30$ & $680+/-74$ \\
\hline $6.5 \mathrm{mM}$ & $670+/-82$ & $1,350+/-125$ & $780+/-92$ & $670+/-73$ & $180+/-25$ \\
\hline
\end{tabular}

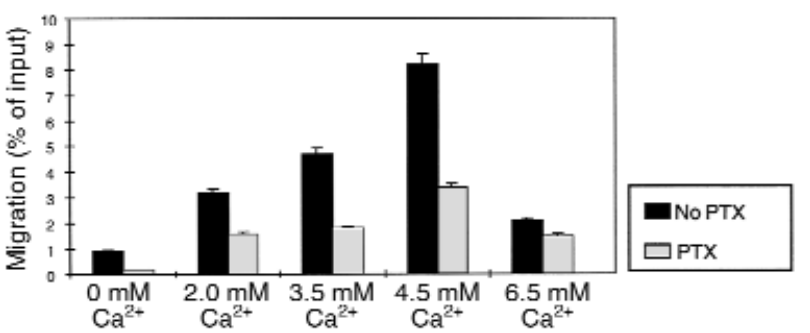

b

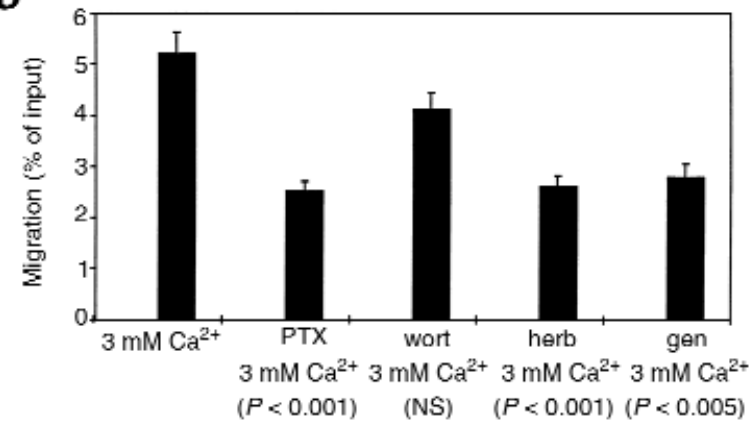

C

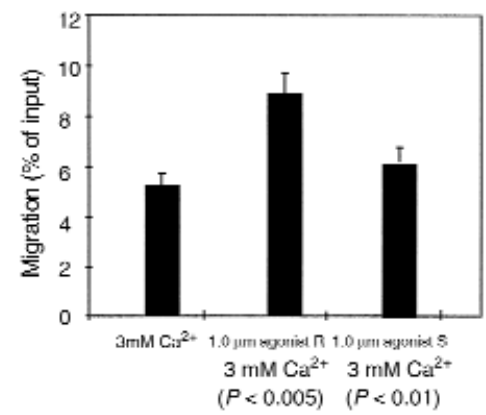

d

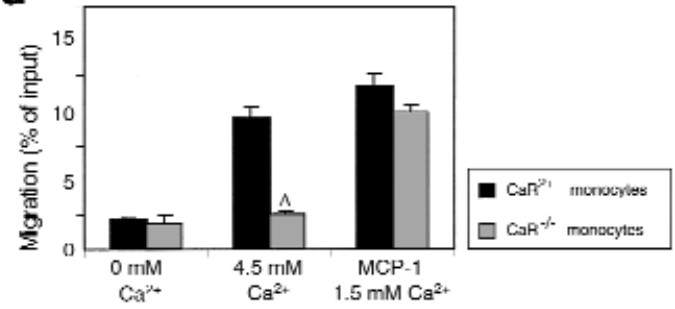

e

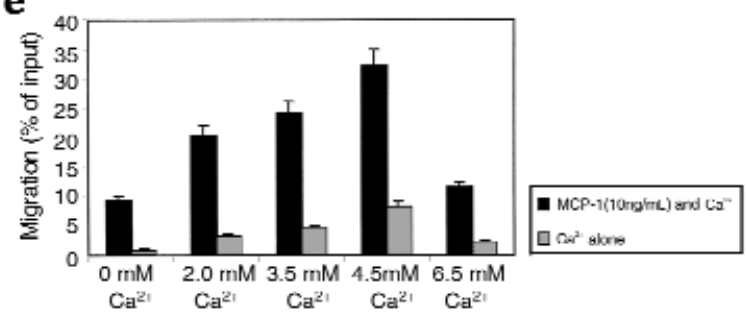

Figure 2

Monocytes migrate toward $\mathrm{Ca}^{2+}$ in a dose-dependent manner that is inhibitable by pretreatment with pertussis toxin, genistein, or herbimycin, and is potentiated by the selective CaR activator NPS R-467 and the chemokine MCP-1. (a) Transmigration assays were used to determine if $\mathrm{Ca}^{2+}$ was capable of inducing monocyte chemotaxis within a checkerboard analysis (upper panel). An input of $10^{4}$ monocytes was used, and the mean numbers of cells migrating in response to each $\mathrm{Ca}^{2+}$ gradient are shown for three independent experiments. A dose-dependent effect was seen, with maximal chemotaxis observed at $4.5 \mathrm{mM} \mathrm{Ca}^{2+}$, which was inhibitable by pretreatment with pertussis toxin (PTX) (lower panel). (b) Chemotaxis of monocytes toward a positive gradient of $\mathrm{Ca}^{2+}$ at $3 \mathrm{mM}$ was also inhibitable by pretreatment with the tyrosine kinase inhibitors genistein (gen) or herbimycin (herb), but not by the Pl-3 kinase inhibitor wortmannin (wort). (c) The role of the CaR in mediating the chemotactic response to elevated $\mathrm{Ca}^{2+}$ was supported by the greater potency of R-467 (agonist R) than of S-467 (agonist S) in stimulating chemotaxis. It should be noted that no specific antagonists or neutralizing antibodies for the CaR have been defined to date. $P$ values represent comparison with 3-mM Ca ${ }^{2+}$ control using the Student's $t$ test. (d) Chemotaxis of PBMC obtained from CaR ${ }^{-/-}$mice and $\mathrm{CaR}^{+/+}$mice also evaluated in response to $4.5 \mathrm{mM} \mathrm{Ca}^{2+}$ and to $\mathrm{MCP}-1$ in the presence of $1.5 \mathrm{mM} \mathrm{Ca}^{2+}$. The percent migration of CaR $\mathrm{R}^{+/+}$monocytes $($black bars) and $\mathrm{CaR}^{-/-}$monocytes (gray bars) are shown. The data from two separate experiments are shown (mean $\pm \mathrm{SEM}$ ). ${ }^{\mathrm{A} P} \mathrm{P}=0.0481$, Student's $t$ test. (e) Chemotaxis of CD14 $4^{+}$monocytes toward a positive concentration gradient of MCP- 1 was also dependent upon and potentiated by $\mathrm{Ca}^{2+}$. Migration of monocytes in the presence of varying levels of $\mathrm{Ca}^{2+}$ with MCP-1 (black bars) or without MCP-1 (gray bars) is shown. The percentage of cells migrating in response to MCP-1 could be augmented by increased $\mathrm{Ca}^{2+}$ concentrations with peak added activity at $4.5 \mathrm{mM}$ $\mathrm{Ca}^{2+}$. Data represent mean \pm SEM of at least three independent experiments.

To confirm the role of $\mathrm{CaR}$ in mediating chemotaxis induced by a calcium gradient, we examined mononuclear cells derived from neonatal $\mathrm{CaR}^{-/-}, \mathrm{CaR}^{+/}$, and $\mathrm{CaR} \mathrm{R}^{+/+}$mice. The cells were capable of chemotactic movement toward MCP-1; however, $\mathrm{CaR}^{-/-}$cells failed to transmigrate to the $\mathrm{Ca}^{2+}$ gradient (Figure $2 \mathrm{~d}$ ), definitively demonstrating the role of the $\mathrm{CaR}$ in the response.

Chemokine receptor interactions. We next evaluated whether calcium interacted with other regulators of monocyte migration by assessing the coexpression of chemokine receptors and the CaR on primary human adult monocytic cells. CCR2 and CCR5 were present on $100 \%$ of CD $14^{+}$PBMC, and CXCR 4 was present on 87\%; coexpression of the CaR with CCR2 was noted in 97\% of CD $14^{+}$PBMC, and coexpression with CXCR 4 was seen in $83 \%$. Functional responses of monocytes to activation of chemokine receptors were then measured in the presence or absence of CaR stimulation using 
transmigration assays. Chemotaxis of $\mathrm{CD} 14^{+} \mathrm{PBMC}$ to a positive concentration gradient of MCP-1 was dependent upon extracellular calcium, as has been reported by others $(28,29)$, whereas MIP- $1 \alpha$ and SDF$1 \alpha$ induced migration independent of calcium (data not shown). The percentage of cells migrating in response to $\mathrm{MCP}-1$ could be augmented by raising extracellular $\mathrm{Ca}^{2+}$, with peak activity noted at $4.5 \mathrm{mM}$ $\mathrm{Ca}^{2+}$ (Figure 2e). The increase in transmigration elicited by a combination of MCP- 1 and elevated $\mathrm{Ca}^{2+}$ concentrations was greater than the sum of transmigration evoked by either MCP-1 or $\mathrm{Ca}^{2+}$ alone, indicating the synergistic nature of the interaction. In contrast, no synergistic effect was noted when either MIP- $1 \alpha$ or SDF- $1 \alpha$ was used in conjunction with added $\mathrm{Ca}^{2+}$.

The mechanism by which $\mathrm{Ca}^{2+}$ enhanced responsiveness to MCP-1 was evaluated by assessing receptor expression kinetics after CaR stimulation. Exposure of cells to elevated $\mathrm{Ca}^{2+}$ resulted in upregulation of cellsurface CCR 2 at 3 hours (Table 1). In contrast, antibodies directed against CCR5 failed to demonstrate any change in median fluorescence intensity, whereas CXCR4 expression increased but did not achieve statistical significance. Similarly, the fluorescence intensity of anti-CD4 antibody staining did not vary with $\mathrm{Ca}^{2+}$ concentration, thereby excluding a nonspecific enhancement of antibody staining in the presence of increased calcium. Inhibition of new protein synthesis by cycloheximide had no effect on the $\mathrm{Ca}^{2+}$-mediated upregulation of CCR2, indicating that $\mathrm{Ca}^{2+}$ altered receptor processing or trafficking (or both) between cell-surface and intracellular pools, rather than the generation of new receptor molecules.

To assess whether there was reciprocal regulation of the CaR by chemokine receptors, we evaluated CaR surface expression on cells before and after exposure to the chemokines SDF- $1 \alpha$ or MCP- 1 . The mean fluorescence intensity of CaR expression was $361 \pm 25$ units (mean \pm SEM) for untreated monocytes, and rose to $673 \pm 59$ after MCP-1 stimulation. Monocytic expression of CaR rose to $519 \pm 48$ with SDF- $1 \alpha$ treatment.

\section{Table 1}

Exposure of CD14+ monocytes to $\mathrm{Ca}^{2+}$ enhances CCR2 expression in a dose-dependent manner

Mean fluorescence intensity of CCR2

$\begin{array}{lcc} & \text { Mean } \pm \text { SEM } & P \text { value } \\ 0 \mathrm{mM} \mathrm{Ca}^{2+} & 204 \pm 16 & - \\ 1.5 \mathrm{~m} \mathrm{M} \mathrm{Ca}^{2+} & 278 \pm 39 & 0.0045^{\mathrm{A}} \\ 2.5 \mathrm{~m} \mathrm{M} \mathrm{Ca}^{2+} & 296 \pm 35 & 0.0007^{\mathrm{A}} \\ 4.5 \mathrm{mM} \mathrm{Ca}^{2+} & 307 \pm 35 & 0.0003^{\mathrm{A}} \\ 1.5 \mathrm{mM} \mathrm{Ca}^{++} \text {and agonist R } & 460 \pm 52 & 0.0135^{\mathrm{B}} \\ 1.5 \mathrm{mM} \mathrm{Ca2+}^{2+} \text { and agonist S } & 417 \pm 48 & 0.0205^{\mathrm{B}}\end{array}$

Monocytes were exposed to varying concentrations of $\mathrm{Ca}^{2+}$ and to the selective CaR activator NPS R-467 $(1 \mu \mathrm{M})$ or NPS S-467 $(1 \mu \mathrm{M})$ in the presence of $1.5 \mathrm{mM} \mathrm{Ca}^{2+}$. The median fluorescence intensity for CCR2 expression was measured for each $\mathrm{Ca}^{2+}$ concentration and in the presence of NPS R-467 or NPS S-467. Mean values \pm SEM from three independent experiments are shown. ${ }^{\text {AS }}$ tudent's $t$ test vs. $0 \mathrm{mM} \mathrm{Ca}^{2+}$; ${ }^{B}$ Student's $t$ test vs. $1.5 \mathrm{mM} \mathrm{Ca}^{2+}$.
In vivo monocyte migration toward calcium. To determine whether $\mathrm{Ca}^{2+}$ was active as a chemoattractant for monocytes in vivo, $\mathrm{Ca}^{2+}$ alone $(5.0 \mathrm{mM}), \mathrm{MCP}-1$ alone, or both $\mathrm{Ca}^{2+}$ and MCP-1 were injected subcutaneously into $\mathrm{C} 57 \mathrm{BL} / 6$ mice, and the tissue was excised 18 hours later. Accumulation of mononuclear cells staining positive for the monocytic marker Mac1 was noted in mice injected with either $\mathrm{Ca}^{2+}, \mathrm{MCP}-1$ (Figure 3), or $10 \mu \mathrm{M}$ NPS R-467. No subcutaneous infiltrates of cells were detected in mice injected with PBS alone. The greatest degree of monocyte infiltration into subcutaneous tissues was seen with $5 \mathrm{mM}$ $\mathrm{Ca}^{2+}$ plus MCP-1, supporting in vivo the synergistic relationship observed in vitro (Figure 3 ). No significant infiltrate of neutrophils into the site of subcutaneous injection was seen under any of the conditions used, as determined by hematoxylin and eosin staining of skin sections.

\section{Discussion}

Ionic calcium is highly regulated in vivo, yet can be elevated in specific tissue microenvironments such as the bone marrow, and is particularly altered in the context of ongoing cell death and inflammation. Hypothesizing that this phenomenon may serve as a primitive regulator of immune cells, we examined a number of hematopoietic cell types for expression of the CaR. Whereas this receptor is expressed on primitive hematopoietic cells (I. Olszak, manuscript in preparation), it is strikingly abundant on mature monocytic cells and is therefore a candidate mediator of immunologic function of this member of the innate immune system.

Localization of monocytes/macrophages at sites of injury or inflammation is crucial for initiation of their role in host defense, and has been demonstrated to be regulated by a number of members of the chemokine family. The CaR is a seven-transmembrane-spanning and $G$ protein-coupled receptor that has been shown to have a number of effects on cell physiology (13). A single prior report has indicated that the murine bone marrow stromal cell line ST-2 is capable of chemotaxis in the context of CaR stimulation (18). Whether this molecule alters the motility of primary cells or cells of the immune system had not previously been addressed.

We documented the responsiveness of monocytes to signaling through the $\mathrm{CaR}$ in a $\mathrm{G} \alpha_{\mathrm{i}}$-coupled pathway mediated by tyrosine kinase, but not PI-3 kinase. The activation of this receptor by either polycationic cognate ligands (e.g., high $\mathrm{Ca}^{2+}$ or spermine) or NPS $\mathrm{R}-4 \mathrm{E} 7$, an allosteric activator of the CaR, resulted in the transmigration of monocytic cells, providing a mechanism to explain the prior observation of others that calcium may enhance the migration of monocytes to oxidized LDL (30). The absence of chemotaxis of $\mathrm{CaR}^{-/-}$monocytes toward $\mathrm{Ca}^{2+}$ even though they responded to a control chemokine shows the specificity of the phenomenon for the CaR. Conjecturing that the $\mathrm{Ca}^{2+}$ signal would probably 

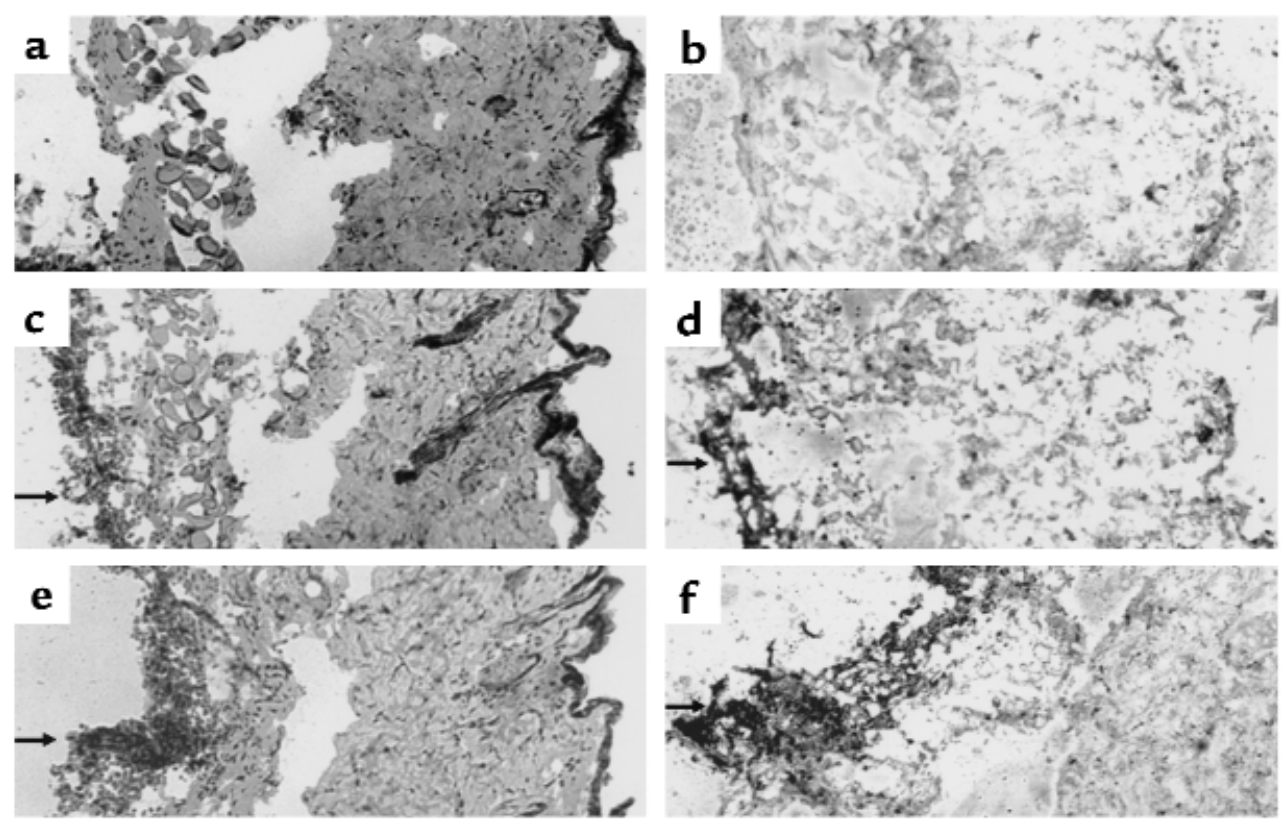

Figure 3

$\mathrm{Ca}^{2+}$ is a chemoattractant for monocytes in vivo. Frozen sections of skin were obtained after subcutaneous injection of mice with PBS alone ( $\mathbf{a}$ and $\mathbf{b}$ ), $5.0 \mathrm{mM} \mathrm{CaCl} 2$ alone (c and $\mathbf{d}$ ), or $5.0 \mathrm{mM} \mathrm{CaCl} 2$ plus $10 \mathrm{ng} / \mathrm{mL} \mathrm{MCP}^{-1}$ (e and f). Sections were stained with hematoxylin and eosin $(\mathbf{a}, \mathbf{c}, \mathbf{e})$ or alkaline phosphatase-conjugated, macrophage-specific Mac-1 antibody (b, $\mathbf{d}, \mathbf{f})$. Occasional cells in skin from mice injected subcutaneously with PBS alone stained positively for $\mathrm{Mac}-1$. However, $\mathrm{CaCl}_{2}$ alone and the combination of CaCl 2 plus MCP-1 caused a dense infiltrate of mononuclear cells that stained positively for Mac-1 (indicated by arrows in $\mathbf{c}, \mathbf{d}$, and $\mathbf{f}$ ). Data are representative of one of two independent experiments.

interact with other mediators of cell response, we assessed whether the migratory response to MCP-1 was similarly modulated by CaR activation. The impact of CaR signaling was manifested in upregulation of MCP-1 receptor, mediated by a mechanism of altered intracellular trafficking rather than new protein synthesis. A reciprocal increase in CaR expression was noted with stimulation of CCR2 with MCP1 , documenting a clear interrelationship of these two unrelated members of the 7-TMR family. This interaction was evident in vivo as well as in vitro when ligands were used in isolation or in combination in animals, and generated marked monocytic infiltrates at the site of injection. Thus ionic calcium serves to directly and indirectly influence monocyte migratory response. It can play a role in the tissue localization of primary monocytes, and may potentiate protein-mediated induction of chemotaxis. The contribution of this signal to inflammation is dependent upon local calcium concentrations, and therefore may be relevant for settings of either extensive injury or in the context of chronic inflammation.

The CaR induction of monocyte infiltration provides insight regarding the persistence of inflammation at sites of prior injury subsequent to resolution of the initiating event. The presence of local calcium may further monocytic recruitment, thereby perpetuating inflammatory infiltration. Sites of local accumulation of calcium such as atherosclerotic plaques, granulomata, calcific tendinitis, or calcium pyrophosphate disease (pseudogout) may provide reservoirs of calcium ions that serve to encourage monocyte localization. Interruption of this chemokinetic stimulus through specific inhibition of the $\mathrm{CaR}$ may provide a therapeutic opportunity in these disease contexts.

\section{Acknowledgments}

The authors gratefully acknowledge contributions from Edward Nemeth, Andrew Luster, Fred Preffer, and David Dombkowsky, and support from the National Institutes of Health (HL-44851 and DK50234 to D.T. Scadden; DK-41415, DK-48330, and DK-52005 to E.M. Brown; and DK-52479 to M.R. Pollack), Defense Advanced Research Projects Administration (to D.T. Scadden), National Space Biomedical Institute (to E.M. Brown), the Richard Saltonstall Charitable Foundation (to D.T. Scadden), the St. Giles Foundation (to E.M. Brown), and the Burroughs-Wellcome Fund (to M.R. Pollack).

\footnotetext{
1. Wells, T.N., Power, C.A., and Proudfoot, A.E. 1998. Definition, function and pathophysiological significance of chemokine receptors. Trends Pharmacol. Sci. 19:376-380.

2. Baggiolini, M. 1998. Chemokines and leukocyte traffic. Nature. 392:565-568.

3. Luster, A.D. 1998. Chemokines: chemotactic cytokines that mediate inflammation. N. Engl. J. Med. 338:436-445.

4. Ma, Q., et al. 1998. Impaired B-lymphopoiesis, myelopoiesis and derailed cerebellar neuron migration in CXCR4- and SDF-1-deficient mice. Proc. Natl. Acad. Sci. USA. 95:9448-9453.

5. Ma, Q., Jones, D., and Springer, T.A. 1999. The chemokine receptor CXCR4 is required for the retention of B-lineage and granulocytic precursors within the bone marrow microenvironment. Immunity. 10:463-471.

6. Ross, R. 1999. Inflammation and atherosclerosis. N. Engl. J. Med.
} 
340:115-126.

7. Menkin, V. 1981. Biochemical mechanisms in inflammation. Charles Thomas Publisher. Chicago, Illinois, USA. 1-21.

8. Lin, C.-Y., and Huang, T.-P. 1991. Enhancement of ionized calcium and 1,25-dihydroxycholecalciferol loss from peritoneal fluid during peritonitis treated with continuous ambulatory peritoneal dialysis. Nephron. 59:90-95.

9. Kaslick, R.S., et al. 1970. Quantitative analysis of sodium, potassium and calcium in gingival fluid from gingiva in varying degrees of inflammation. J. Periodontol. 41:93-97.

10. Tanimura, A., McGregor, D.H., and Anderson, H. 1986. Calcification in atherosclerosis. I. Human studies. J. Exp. Pathol. 2:261-273.

11. McCarty, D.J. 1994. Crystals and arthritis. Dis. Mon. 40:253-299.

12. Brown, E.M., et al. 1993. Cloning and characterization of an extracellular $\mathrm{Ca}^{(2+)}$-sensing receptor from bovine parathyroid. Nature. 366:575-580.

13. Brown, E.M., Quinn, S., Vassilev, P.M., and Hebert, S. 1999. G-proteincoupled, extracellular $\mathrm{Ca}^{2+}$-sensing receptor: a versatile regulator of diverse cellular functions. Vitam. Horm. 55:1-71.

14. Lin, K.I., et al. 1998. Elevated extracellular calcium can prevent apoptosis via the calcium-sensing receptor. Biochem. Biophys. Res. Commun. 249:325-331.

15. Freichel, M., et al. 1996. Expression of a calcium-sensing receptor in a human medullary thyroid carcinoma cell line and its contribution to calcitonin secretion. Endocrinology. 137:3842-3848.

16. McNeil, S.E., Hobson, S.A., Nipper, V., and Rodland, K.D. 1998. Functional calcium-sensing receptors in rat fibroblasts are required for activation of SRC kinase and mitogen-activated protein kinase in response to extracellular calcium. J. Biol. Chem. 273:1114-1120.

17. House, M.G., et al. 1997. Expression of an extracellular calcium sensing receptor in human and mouse bone marrow cells. J. Bone Miner. Res. 12:1959-1970.

18. Yamaguchi, T., et al. 1998. Expression of extracellular calcium $\left(\mathrm{Ca}^{2+}{ }_{\mathrm{o}}\right)-$ sensing receptor in human peripheral blood monocytes. Biochem. Biophys. Res. Commun. 246:501-506.

19. Ho, C., et al. 1995. A mouse model of human familial hypocalciuric hypercalcemia and neonatal severe hyperparathyroidism. Nat. Genet. 11:389-394.

20. Dutour, A. 1996. Calcium-sensing receptor: confirmation of its pivotal function in calcium homeostasis, using a knock-out model. Eur. J. Endocrinol. 134:542-543.

21. Nemeth, E.F., et al. 1998. Calcimimetics with potent and selective activity on the parathyroid calcium receptor. Proc. Natl. Acad. Sci. USA. 95:4040-4045.

22. Chen, C.J., Barnett, J.V., Congo, D.A., and Brown, E.M. 1989. Divalent cations suppress 3',5'-adenosine monophosphate accumulation by stimulating a pertussis toxin-sensitive guanine nucleotide-binding protein in cultured bovine parathyroid cells. Endocrinology. 124:233-239.

23. Varrault, A., et al. 1995. Expression of $\mathrm{G}$ protein alpha-subunits in bovine parathyroid. Endocrinology. 136:4390-4396.

24. Dare, E., Kifor, O., Brown, E.M., and Weber, G. 1998. Characterization of the phosphatidylinositol-specific phospholipase C isozymes present in the bovine parathyroid and in human kidney HEK293 cells stably transfected with the human parathyroid $\mathrm{Ca}^{++}$-sensing receptor. J. Mol. Endocrinol. 21:7-17.

25. Bleul, C.C., et al. 1996. A highly efficacious lymphocyte chemoattractant, stromal cell-derived factor 1 (SDF-1). J. Exp. Med. 184:1101-1109.

26. Quinn, S.J., et al. 1997. The $\mathrm{Ca}^{2+}$-sensing receptor: a target for polyamines. Am. J. Physiol. 273:C1315-C1323.

27. Chattopadhyay, N., Ye, C.-P., Yamaguchi, T., Vassilev, P.M., and Brown, E.M. 1999. Evidence for extracellular calcium-sensing receptor mediated opening of an outward $\mathrm{K}^{+}$channel in a human astrocytoma cell line (U87). Glia. 26:64-72.

28. Sozzani, S., et al. 1991. The signal transduction pathway involved in the migration induced by a monocyte chemotactic cytokine. J. Immunol. 147:2215-2221.

29. Sozzani, S., et al. 1993. Receptor-activated calcium influx in human monocytes exposed to monocyte chemotactic protein-1 and related cytokines. J. Immunol. 150:1544-1553.

30. Shi, H., Severs, N.J., and Robenek, H. 1996. Effects of calcium on the migration and recruitment of macrophages and macrophage derived foam cells. FASEB J. 10:491-501. 